\title{
Methemoglobinemia from curing salt
}

\author{
Michael D. Jain MD PhD, Anna Nikonova MD
}

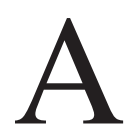
previously healthy 52-year-old Asian woman presented to the emergency department after a syncopal episode. She appeared grey and cyanotic. At $65 \%$ fraction of inspired oxygen, pulse oximetry showed an oxygen saturation level of $86 \%$. Her arterial blood gas had an elevated partial pressure of oxygen (491 mm Hg) and an elevated methemoglobin fraction (55.2\% [normal 1\%-2\%]). She was admitted to the intensive care unit and given ascorbic acid (500 mg) orally and methylene blue $(1 \mathrm{mg} / \mathrm{kg})$ intravenously. Her methemoglobin level improved to $8 \%$ within 2 hours.

On the day of presentation, the patient had prepared her lunchmeat with a white crystalline powder labelled "Nitre Powder," which she had purchased from a local grocer (estimated ingestion $10 \mathrm{~g}$ ). Curing is a common meat-preparation process that uses sodium nitrite salts to improve the colour, texture and flavour of the meat, while reducing bacterial levels. To determine if the powder was the cause, we mixed a few grains of the powder with the patient's arterial blood. Immediately, the blood changed to the classic chocolate-brown colour associated with methemoglobinemia (Figure 1). The methemoglobin fraction of this mixture was elevated.

Methemoglobinemia is a potentially fatal condition caused by the presence of the oxidized ferric $\left(\mathrm{Fe}^{3+}\right)$ heme that leads to poor oxygen delivery to tissues. It can be congenital but is usually acquired. Commonly used medications associated with methemoglobinemia include benzocaine, nitroprusside and dapsone. ${ }^{1}$ It is also associated with cured meat products, ${ }^{2}$ water contaminated with nitrite fertilizers, recreational drugs and, in the developing world, copper sulfate-containing pesticides. ${ }^{1}$ Methemoglobinemia presents with hypoxia (detected by pulse oximetry) and high oxygenation of arterial blood (detected by blood gas analysis). A methemoglobin fraction over $30 \%$ is considered life-threatening and is reported with the arterial blood gas results on most modern analyzers. ${ }^{1}$

Treatment for methemoglobinemia consists primarily of methylene blue given intravenously and, less effectively, ascorbic acid. Methylene

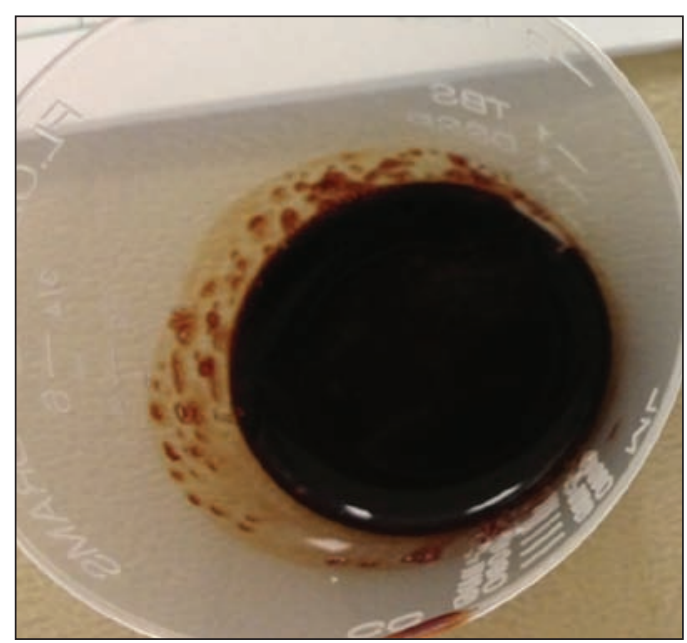

Figure 1: Chocolate-coloured arterial blood associated with methemoglobinemia.

blue is contraindicated for patients with glucose6-phosphate dehydrogenase (G6PD) deficiency; therefore, a history of hemolysis should be ruled out before treatment. Red cell exchange and hyperbaric oxygen can also be used, depending on clinical severity. ${ }^{1}$ With some substances, methemoglobinemia recurs after initial treatment, so patients need to be monitored carefully. ${ }^{3}$ Our patient's risk of relapse was low because of the short half-life of oral sodium nitrite. She did not have G6PD deficiency and was discharged home less than 48 hours after ingestion; at that time, she had a methemoglobin fraction of $1.6 \%$. We reported this case to the Canada Vigilance Program, which is Canada's postmarketing surveillance program for adverse outcomes from health products. ${ }^{4}$

\section{References}

1. El-Husseini A, Azarov N. Is threshold for treatment of methemoglobinemia the same for all? A case report and literature review. Am J Emerg Med 2010 28:748.e5-748.e10.

2. Khan A, Adams A, Simmons G, et al. Deadly meatballs - a near fatal case of methaemoglobinaemia. N Z Med J 2006;119:U2107.

3. Moulis G, Bagheri H, Saint Martory J, et al. Very late relapse of dapsone-induced methaemoglobinemia. Eur J Clin Pharmacol 2010;66:645-6.

4. Canada Vigilance Program. Ottawa (ON): Health Canada; 2011 Available: www.hc-sc.gc.ca/dhp-mps/medeff/vigilance-eng.php (accessed 2012 Nov. 4).
Competing interests: None declared.

This article has been peer reviewed.

Affiliation: From the University of Toronto, Toronto, Ont.

Acknowledgements: The authors thank Dr. Richard Ward, Department of Hematology, University Health Network, Toronto, Canada, for comments on this report.

Correspondence to:

Michael D. Jain, michael.jain@mail.utoronto .ca

CMAJ 2013. DOI:10.1503 /cmaj.121714 